\title{
LA LITERATURA SALAZARISTA ANTE LA GUERRA DE ESPAÑA. POESÍA Y PROPAGANDA EN CORREIA LEITE, FREITAS SOARES Y VIEIRA DA CRUZ
}

\author{
ANTONIO RIVERO MACHINA ${ }^{1}$ \\ Universidad de Extremadura
}

\begin{abstract}
Resumen
El presente artículo ofrece una panorámica en torno a la literatura propagandística escrita en el Portugal de Salazar en apoyo a los militares sublevados durante la Guerra Civil española (1936-1939). De manera particular, las siguientes líneas se centran en el género poético como medio de propaganda, especialmente en los poemarios escritos por los poetas portugueses Ruy Correia Leite, António de Freitas Soares y Tomaz Vieira da Cruz para tal fin.
\end{abstract}

Palabras clave. Literatura y propaganda, Guerra Civil española, Poesía portuguesa.

\begin{abstract}
This article gives an overview of the propaganda literature written in the Salazar's Portugal to support the military rebels during the Spanish Civil War (1936-1939). In particular, the following lines focus on the poetic genre as a kind of propaganda, especially in the poems written by the Portuguese poets Ruy Correia Leite, António de Freitas Soares and Tomaz Vieira da Cruz for that purpose.
\end{abstract}

Key words. Literature and propaganda, Spanish Civil War, Portuguese poetry

El corresponsal Leopoldo Caballero López firmaba en 1960 para $A B C$ un reportaje al que había titulado "Camoens, en Ceuta". Tales líneas giraban en torno a la huella del autor de Os Lusíadas y su militar estadía en aquella ciudad africana. Desde su enclave, de inconfundible connotación legionaria, Caballero acudía al recuerdo tomándoles la imagen al Pedro de Lorenzo de Y al oeste Portugal (Madrid, Editora Nacional, 1946) ${ }^{2}$ y al Ernesto Giménez Caballero de Amor a Portugal (Madrid, Cultura Hispánica, 1949)- de los "mutilados" más ilustres de la historia ibérica compartida:

Coincidencia de dos glorias del "bloque ibérico" literario: Camoens, gemelo de Cervantes. Dualidad asombrosa, trayectoria idéntica desde su nacimiento (incluso disputarse dos lugares,

\footnotetext{
${ }^{1}$ Universidad de Extremadura. Correo: antoniorm@unex.es. Recibido: 25-05-2015. Aceptado: 09-04-2015.

2 "Ni a don Juan de Austria, que es uno de los niños, ni al rey don Sebastián, que es el otro, le faltarían las asistencias poéticas: la acción de los dos grandes del Iberismo. Tiritando de tercianas, Miguel, que es uno de los grandes, pierde una mano, a la mayor honra de don Juan. Y Luis -Luis Vaz de Camöes-, el otro grande, pierde un ojo, pero mide en octavas reales Os Lusíadas para ejercicio de la rota heroica donde moriría su rey doncel. Un mismo cantor, Fernando de Herrera, inmortaliza la hazaña de aquellos dos niños" (De Lorenzo, 1973: 106).
} 
respectivamente, la honra de ser cuna de cada uno). Parecidas sus penalidades, mutilados frente a común enemigo. "Manco de Lepanto" y "Divino Tuerto" son sus títulos gloriosos ( $A B C$ Madrid, 5 de mayo de 1960, p. 27).

Esta advocación al tuerto y al manco como gloria y blasón de las naciones ibéricas venía a simbolizar en cierta medida la retórica más nostálgica y exaltada del estamento intelectual afecto al Estado Novo del salazarismo y al Movimiento Nacional franquista durante sus varias décadas de vida. Una nostalgia por el Imperio perdido que dio aliento y rumbo a buena parte de la retórica propagandística de ambos regímenes durante su década fundacional, la de los años treinta. Elevados Camões y Cervantes a la categoría de escritores nacionales por antonomasia desde el liberalismo constitucional decimonónico, se les añadía en textos como este el paralelismo de haber empeñado parte de su fisonomía en la guerra contra el infiel. Orlaba así la vieja disputa cervantina de las armas y las letras el mensaje militarista de dos dictaduras hermanadas bajo el común objetivo de sobrevivirse a sí mismas. Dos dictaduras que encontraron en los años de la guerra civil española su particular espacio para la épica.

Con ínfulas imperiales y motivaciones mucho más pragmáticas en la menuda historia de una guerra fratricida se nos revela la abundante poesía escrita por no pocos autores lusos a lo largo de los años que median entre 1936 y 1939 en el país vecino. Como inevitable producto propagandístico de su tiempo, la literatura salazarista en torno a la "guerra de Espanha" legará textos poéticos fácilmente reconocibles en lo que a su retórica, estructura formal y tópica literaria se refiere. Más allá de su discutible valor literario, el conocimiento y estudio de tal corpus poético se nos revela, en cualquier caso, fundamental para el correcto conocimiento del hecho histórico frente a la idea generalizada de que las letras tomaron inequívocamente la causa de un único bando.

\section{LITERATURA Y PROPAGANDA EN FAVOR DE LOS SUBLEVADOS}

No en vano, la sublevación militar del 18 de julio gozó en Portugal de no pocas simpatías y adhesiones, más allá de la cobertura logística y diplomática brindada por el Estado Novo a los sediciosos. La maquinaria propagandística de António Ferro, pero también la labor voluntaria de otros tantos creadores y escritores lusos difundieron su propia literatura de apoyo a los nacionalistas y escarnio contra un bando republicano al que equiparaban con las peores prácticas del estalinismo. Estas publicaciones no sufrieron, lógicamente, las restricciones y censuras padecidas por los textos de signo contrario (Pena Rodríguez, 2012). Asimismo, la difusión de la literatura de guerra del bando nacionalista español fue conocida y accesible en todo Portugal durante la contienda, favorecida expresamente por el régimen. Paradójicamente, su difusión hoy es inversamente proporcional respecto a la de entonces y la bibliografía crítica muy escasa $^{3}$, siendo muchas de estas piezas de propaganda filofascista desconocidas para la crítica.

\footnotetext{
${ }^{3}$ Dicha escasez ha sido relativamente compensada por la minuciosa tesis doctoral de Alberto Pena Rodríguez, El Estado Novo de Oliveira Salazar y la Guerra Civil española: información, prensa y propaganda (1936-1939), Madrid, Universidad Complutense, 1997.
} 
Frente a la bien documentada y ampliamente estudiada poesía de simpatía al bando republicano, incluyendo posteriores antologías de enorme impacto como $A$ guerra civil de Espanha na poesia portuguesa de Joaquim Namorado (Coímbra, Centelha, 1987), el corpus literario afecto a los militares sediciosos es escasamente conocido. Para la poesía de guerra del bando rebelde en Portugal apenas encontramos una tardía recepción en el tomo antológico de António Manuel Couto Viana Por outras palavras (Lisboa, Vega, 1997). Veinticinco años antes, el escritor de Viana do Castelo ya había traducido 10 poesias sobre a Guerra Civil espanhola de Agustín de Foxá (Coimbra, Cidadela, 1972). Por su parte, Por outras palavras, florilegio de sus traducciones poéticas, se culminaba con una particular colección de "Poemas nacionalistas da Guerra Civil de Espanha" (Couto Viana, 1997: 81-147). Con su publicación, las intenciones de Couto Viana se hacen explícitas:

Ainda que, no sector nacionalista, a Guerra Civil de Espanha não tenha motivado obras excepcionais de Poesia, é, no entanto, injusto votar ao esquecimento os nomes, por exemplo, de José María Pemán, Dionísio Ridruejo, Álvaro Cunqueiro e Agustín de Foxá (Conde de Foxá), cuja inspiração não ficou alheia à luta ideológica que lhes agitou violentamente a Pátria (...). Esse, perante Rafael Alberti ou Miguel Hernández (estes, sim, largamente divulgados), aqueles poetas perderam a guerra, não deixam, todavía, de ocupar lugar honroso numa antología que reúna produções poéticas das duas trincheiras militantes.

Como contributo (pobre) para o conhecimento, entre nós, de alguns textos importantes que permitam um juízio imparcial sobre a literatura espanhola durante os anos de 1936 a 1939, traduziram-se e dão-se à estampa estas poesias, chagadas até mim, durante o conflito espanhol, entusiasmando a minha juventude que aprendía a amar, conscientemente, a Pátria, a Beleza, o Heroísmo (Couto Viana, 1997: 83).

Sus simpatías franquistas, además de obvias, revelan una influencia juvenil -y no tan juvenil- en determinados autores lusos, como el propio Couto Viana, análoga a la experimentada por los jóvenes poetas neorrealistas y allegados a propósito del bando leal a la República. Recuerdo maduro de estas pasiones juveniles será el que aparezca en un poema de Couto Viana publicado en su poemario O Senhor de Si (Lisboa, Átrio, 1991):

Menino, ouvi que a patria da minha Mãe, a Espanha,

Fuzilava, vermelha, na frontera

Que o rio Minho banha,

O Fidalgo, o burgués, o padre, a freira.

Logo a minha cidade

Se encheu de fugas precipitadas.

E havia mais convívio e liberdade

No cinema, nos jardins, nas esplanadas.

Falava-se galego em toda a parte.

E eu via, com alegre sobressalto,

Um comboio de víveres que parte;

Um joven que se alista, braço ao alto.

Morrera minha Avó ao cercarem Oviedo.

González Peña, seu sobrino,

Combatia em Madrid. Mas isto era um segredo

Que feria a familia como a espada do espinho. 
O hino Cara al Sol, com a letra tão bela,

Cantava-o minha Mãe. Clarim nos meus ouvidos!

E, enquanto eu me sonhava de guarda a cada estrela,

Sem distinção de credos, era Ela

Que me punha a rezar por todos os caídos! ${ }^{4}$

Las traducciones de Couto Viana suponen, en cualquier caso, un testimonio inequívoco de la fluida circulación en Portugal de estas composiciones durante la contienda, entre las que destacan las piezas de Agustín de Foxá5

En este contexto, testimonios de denuncia contra los desmanes de los sublevados como el de Miguel Torga en A Criação do Mundo (Coímbra, Ed. del autor, 1937-1939) ${ }^{6}$ tuvieron su contrarrelato en volúmenes como D. Quixote bolchevick (Lisboa, Livraria Clássica, 1936), firmado por el abogado lisboeta Alfredo Ary dos Santos. Entre sus páginas leemos un alegato anticomunista exacerbado, donde la impresión causada por la ciudad deSalamanca, cuyas visitas durante los primeros meses de contienda suponen la materia prima del libro, queda diametralmente alejada de la que experimentará Torga meses después. Las páginas de D. Quixote bolchevick agavillan toda una serie de espantosos horrores perpetrados supuestamente -el autor se limita a hacerse eco de cuanto a sus oídos llega, sin mayor afán de contraste- por las facciones rojas. El objetivo último de estas, para el autor, era la aniquilación misma del espíritu español, pintando en consecuencia un panorama que no podría ser más dantesco:

Inccensiaram-se casas e templos, fuzilaram-se velhos, violaram-se mulheres, esquartejam-se crianças para inspirar terror, para afirmar superioridade de fôrça, para marcar bem que, por onde passam as hordas de Moscovo, é inútil tentar fazer passar outras bandeira que não seja a bandeira negra da norte ou a rubra do sangue (Ary dos Santos, 1936: 102).

El principal órgano de difusión para estas adhesiones nacionalistas fue el Secretariado de Propaganda Nacional del otrora orfista António Ferro ${ }^{7}$, cuyo presupuesto se disparó durante los primeros compases de la guerra en España. Lo hizo no solo

\footnotetext{
${ }^{4}$ Tomado de (Magalhães, 1999: 283-284).

${ }^{5}$ Los poemas traducidos por Couto Viana son mayoritariamente obra de Foxá: "Trincheiras na frente de Madrid", "A brigada do amanhecer", "Poema da antiguidade de Espanha", "Romance de Onésimo Redondo", "Hino da juventude", "O Cid rumo ás hortas", "A espiga", "Balada de Abril", "A guerra castelhana", "Aquele barco com um nome de ilha", "As brigadas que chegaram do mar", "A meia Espanha cativa", "A Calvo Sotelo" y "Romance de Abdelacid". Completan la antología Álvaro Cunqueiro con "César, escuta como cantas", Dionísio Ridruejo con "A José Antonio", Eugenio Suárez con "Passa a Brigada do Amanhecer", José María Pemán con "Poema da besta e do anjo", Miguel Martínez del Cerro con "Canto para a Espanha desejada" y Federico Urrutia con los poemas "Romance de Castela em armas" y "Suspiro na noite em guerra".
}

${ }^{6}$ Fue el tercer volumen, A Criação do Mundo III. O Quarto Dia (Coímbra, 1939) el testimonio más revelador y explícito publicado entonces por un escritor portugués de primera línea en favor de la maltrecha democracia española. El volumen fue prohibido y retirado de la circulación hasta su reedición en 1971. Miguel Torga fue puesto en prisión, entre diciembre de 1939 y febrero de 1940, en Leiria primero y en la tristemente célebre cárcel de Aljube más tarde.

${ }^{7}$ Ferro firmó numerosos artículos anticomunistas y de adhesión a la causa "nacional" española. Sirvan de ilustración sus colaboraciones en el Diário de Notícias con artículos como "A miragem comunista" (12/09/1936, p. 1), “Na Espanha espanhola” (02/12/1936, p. 1) y “O Milagre de Burgos" (17/12/1936, p. 1). 
contando con una amplia nómina de periodistas portugueses a sueldo encargados de propalar las "satánicas" tropelías del bando republicano en los grandes medios del país, sino que además el SPN protegió y sufragó trabajos de autores españoles como Manuel Falcón, Carmen de Lara, el marqués de Quintanar, Julio Camba, Lasso de la Vega, Eugenio Montes, Álvaro de las Casas o Eugenio d'Ors (Pena Rodríguez, 1997: 139-140 y 536). La prensa del régimen, sobre todo en periódicos como el Diário da Manhã, O Comércio do Porto y el Diário de Notícias, o en revistas como Ocidente, Alma Nacional y Aviz, se ocupará de la puntual publicación de muchos de sus textos, ya fuera en portugués o en castellano. Por citar un ejemplo, pocos días después del alzamiento encontramos a Manuel Falcón firmando en el periódico A Voz su particular "Arriba España!":

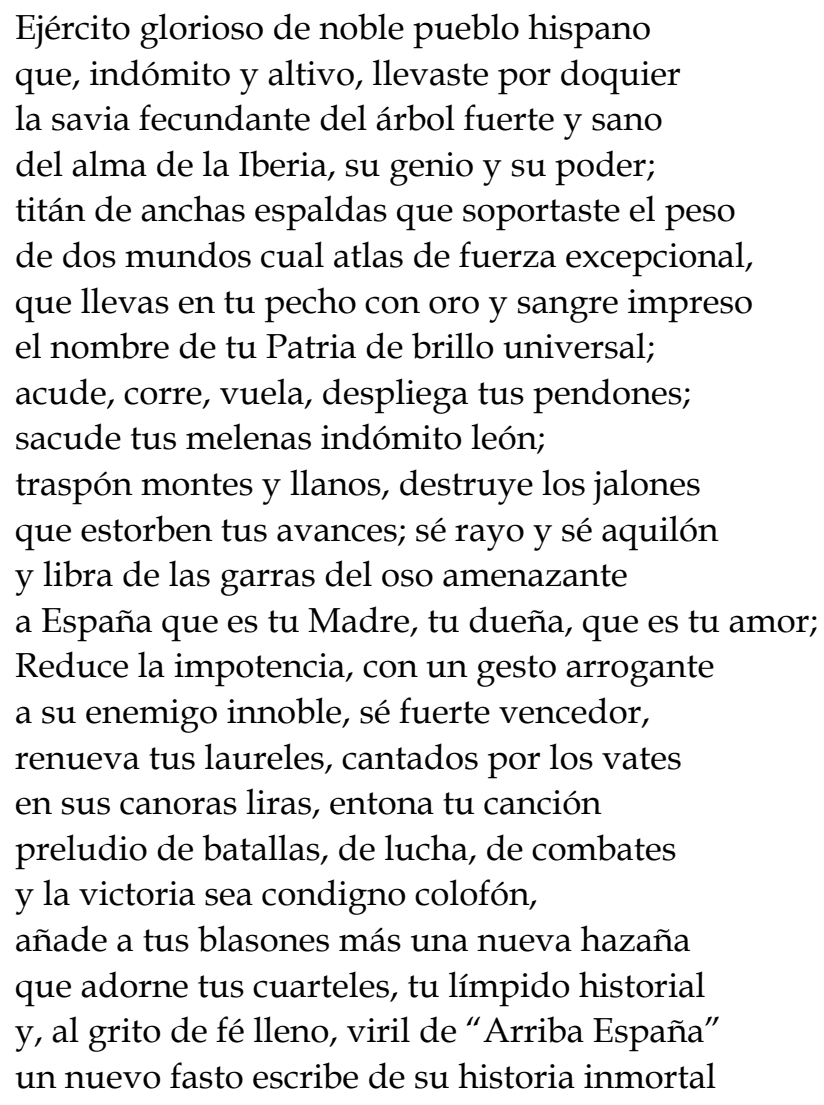

Entre estos intelectuales protegidos por el salazarismo durante los prolegómenos y primeros compases de la contienda española destacan sobremanera determinadas personalidades. Figura clave como enlace entre la aristocracia y alta burguesía española exiliada en Portugal -con base en Estoril- y los militares insurgentes, fue un viejo conocido de las relaciones literarias hispano-portuguesas. Nos referimos al poeta e historiador Fernando Gallego de Chaves y Calleja, distinguido como el marqués de Quintanar, quien entre otros servicios envió al gobierno de Burgos todas las alianzas, monedas, collares y demás objetos de oro reunidos por las damas de la alta sociedad española de Estoril -la condesa de Puerto Hermoso y Rojas, la duquesa de Medina Sidonia o las marquesas de Argüelles, de Vega de Anzo, de Claramunt, de La Granja y de Liesta, entre otras- con el elevado fin de sufragar la rebelión contra la legitimidad 
republicana ("Ouro para Espanha”, A Voz, 22 de agosto de 1936, p. 1). Otro escritor español de primera línea patrocinado por la maquinaria propagandística del Estado Novo fue aquel "amigo" de Ary dos Santos al que se daba por fusilado en D. Quixote bolchevick y que, tras un rocambolesco periplo por embajadas y aduanas, logró salir vivo de las líneas republicanas. Nos referimos al novelista gallego Wenceslao Fernández Flórez, quien habría llegado el 24 de mayo de 1938 a la lisboeta estación de Rossio para ser recibido con todos los honores por el presidente del Sindicato Nacional dos Jornalistas y por representantes del SPN en calidad de insigne superviviente del "genocidio rojo". Poco después, el 8 de junio, ofrecía una conferencia sobre las virtudes del nacionalismo español y "O Terror Vermelho" en el palacete lisboeta de São Pedro de Alcántara -a la sazón flamante nueva sede del SPN-, siendo presentado por el propio António Ferro (Pena Rodríguez, 1997: 143 y 539).

Veterano poeta del ultraísmo español, asiduo de publicaciones galleguistas como Nós, discípulo de Ortega y Gasset en la Universidad Central de Madrid y miembro de pleno derecho del "otro" Veintisiete, Eugenio Montes terminó por configurarse como falangista de primera hora y uno de los más estrechos colaboradores de José Antonio Primo de Rivera en la fundación de su partido. Este notable escritor gallego fue, no por casualidad, uno de los activos culturales españoles de mayor peso y consideración en la capital portuguesa durante los años centrales del Estado Novo. Así fue desde su nombramiento como director del Instituto Español de Lisboa por el gobierno de Burgos y su Comisión de Cultura y Enseñanza -a cuyo frente estaba José María Pemán-, en marzo de 1937, y hasta su traslado en noviembre de 1954 (Chica Blas, 2012: 117 y 137). Montes no tardó en poner su oratoria y su prosa al servicio de la guerra pronunciando conferencias como la celebrada el 14 de mayo de 1937 en el Teatro Trinidade o firmando artículos de opinión en favor del Alzamiento Nacional ("De Dostoievski a Estaline", Diário da Manhã, 14 de mayo de 1937, pp. 3 y 7).

Precisamente José María Pemán fue otra de las figuras de relumbrón por aquellos meses en la sociedad salazarista. El poeta gaditano visitó el país vecino en varias ocasiones durante la guerra, siempre en misiones de propaganda. El primero de estos viajes se produjo a finales de agosto de 1936, con el fin de formar parte del multitudinario "comicio anti-comunista" de la plaza de toros de Campo Pequeno, en calidad de "uma das mais brilhantes figuras da Espanha intelectual contemporânea" (O Século, 29 de agosto de 1936, p. 6). Un mes más tarde Pemán regresaba a Portugal, en esta ocasión para arengar por la causa "nacional" desde la emisora del Radio Clube Português que dirigía Botelho Moniz (Pena Rodríguez, 1997: 549). En mayo de 1937 un Pemán encumbrado ya como ministro de Cultura del gobierno de Burgos vuelve a visitar Lisboa para participar en unos Jogos Florais Luso-Espanholes con un discurso inaugural en el que pone en práctica toda la retórica franquista del momento $\left(A V_{o z}, 25\right.$ de mayo de 1937, pp. 1 y 6). La trascendencia de su figura como "uno de los principales faroles de la cultura franquista para la prensa portuguesa" (Pena Rodríguez, 1997: 550) se hizo patente con su presencia en tribuna, junto a Nicolás Franco, en los actos de homenaje realizados a Os Viriatos -milicias "voluntarias" que combatieron en España junto a los sublevados- en el Teatro São Luiz de Lisboa el 13 de junio de 1939. 
El aparato oficial de propaganda portugués de António Ferro se coordinó oportunamente con el faccioso Servicio Nacional de Propaganda de Burgos. Su jefe, el joven poeta falangista Dionisio Ridruejo, supervisará personalmente el envío a Portugal de abundante material propagandístico (Pena Rodríguez, 1997: 144). A buen seguro, Ridruejo no escatimó composiciones poéticas inspiradas por la causa "nacional" entre todos los materiales doctrinales y propagandísticos enviados al país vecino. En una carta suya adjunta a uno de estos envíos dirigidos al embajador faccioso en Lisboa y hermano del líder de los sublevados, Nicolás Franco, leemos:

Tengo el honor de poner a su disposición postales de SE. el Generalísimo y José Antonio junto con varios carteles editados por este Servicio Nacional. Esta propaganda ha sido seleccionada con el propósito de completar un envío anterior de libros, folletos y publicaciones análogas de carácter doctrinal que fue remitido directamente a la Comisión Organizadora de la Gran Fiesta de Confraternización Anticomunista, (...) así como una serie de fotografías de barbaridades cometidas por los marxistas y de documentos que muestran la intervención soviética en la destrucción de nuestra Patria (Archivo General de la Administración, Exteriores, caja no 6638. Oficio de referencia 5. 236 A.K. del Jefe del Servicio Nacional de Propaganda a Nicolás Franco, 16/11/1938).

En cualquier caso, la tentativa de un ejercicio poético conjunto más destacada por los medios de la época fue la arcaizante y sintomática convocatoria del periódico $A$ Voz de los ya mencionados Jogos Florais Luso-espanholes no estilo do século XIV, celebrados el 24 de mayo de 1937 en el Teatro São Luiz de Lisboa con el fin de recaudar fondos para los hospitales del ejercito sedicioso (Pena Rodríguez, 1997: 617-620). Se trató, fundamentalmente, de un nuevo acto de adhesión y afirmación social de aquel sector de la aristocracia peninsular reunido en torno al salazarismo y los sublevados de España. En la comisión organizadora tomaron parte damas de la alta sociedad portuguesa, correspondiendo la presidencia honorífica a los directores de las principales cabeceras periodísticas del país, así como a señaladas personalidades académicas y literarias como Antero de Figueiredo, Eugénio de Castro o Júlio Dantas, entre otros. El jurado estuvo formado por el director de $A$ Voz junto a poetas tales como Afonso Lopes Vieira o el marqués de Quintanar. Los juegos se constituyeron en dos "cortes", la española y la portuguesa, con la misión de competir por realizar la mejor apología del país vecino. Ambas cortes, constituidas efectivamente por damas de las respectivas noblezas nacionales, contaron con su "mantenedor", siendo José María Pemán el protector de la corte española al tiempo que el escritor Alberto Pinheiro Torres hacía lo propio con la portuguesa. Más allá del discurso de Pemán, la presencia poética española en tal encuentro fue más bien escasa. Frente a la larga lista de laureados y mencionados portugueses, encontramos por España los poemas premiados de "A mi patria" del sacerdote Optaciano de la Vega del Río, "La Falange femenina española” de Víctor M. Sola y "Tríptico teologal” de Adela de Medina (Pena Rodríguez, 1997: 620). De aquel encuentro, más aristocrático que poético, salió un volumen con todos los trabajos presentados y una recaudación de 32000 escudos (A Voz, 27 de mayo de 1937, p. 1).

Un caballo de batalla como pocos para la intelligentsia salazarista fue desmentir los grandes mitos del republicanismo español. Podemos comprobarlo con las figuras de Dolores Ibárruri y José Miaja, pero sucederá lo mismo con célebres episodios de 
represión "nacional", tales como la matanza de Badajoz o el emblemático bombardeo sobre Guernica. De patraña propagandística los tildó la prensa afecta al régimen del Estado Novo:

Quen se der o duvidado de seguir diáriamente o noticiário fornecido aos jornais pelas agências de informação internacional há-de em pouco tempo aperceber-se de que é alvo de discreta propaganda das várias ideologias políticas que se defrontam no Mundo. As agências afectas ao "esquerdismo europeu", bombardear-lhe-ao o espírito com a palavra democracia e seus derivados a-propósito e a despropósito de tudo. Democracia é a palavra mágica que serve para toda a espécie de propaganda, e, em especial, nestes ultimos tempos, do comunismo hispanosoviético... Esta pertinaz preocupação de conquistar a opinião pública mundial -não importa por que meios- para algumas almas de reputação duvidosa, é um triste "sinal dos tempos". Lembramo-nos, por exemplo, do clamor ainda há pouco tempo levantado contra os nacionalistas espanhóis, por causa do incêndio de Guernica. Esse falso clamor condõeu o Mundo. Até espiritos de rara condição intelectual de entre os católicos franceses se deixaram influenciar pela mentira gritada com criminosa hipocrasia pelas turbas da imprensa do "esquerdismo europeu". O incêndio fôra, como o de Irun e o de Eibar, provocado e ateado pelos comunistas, mas propositadamente atribuido aos nacionalistas com o fim de levantar contra êles a opinião internacional (Diário da Manhã, no 2182, 15 de mayo de 1937, p. 1).

Tampoco se desentenderá Portugal de la infame y macabra competición por denunciar más fusilamientos de tantos intelectuales, artistas y escritores -ejecuciones reales o inventadas, seguras o probables-, en uno $\mathrm{u}$ otro bando. A tal se recurre en las páginas del citado D. Quixote bolchevick cuando se menciona "a sorte inglória dos Quinteros, de Jacinto Benavente e do meu amigo Wenceslao Fernandez Florez, que parece terem sido fusilados pelos bandos às ordens de Moscovo e de Paris" (Ary dos Santos, 1936: 25). Por su parte, en septiembre de 1936 António Ferro firmaba un artículo en prensa titulado “Quem protesta?” en el que se preguntaba

Onde estavam quando as balas marxistas, bêbedas de sangue e ódio, fizeram cair para sempre esse intelectual puro que se chamou Ramiro de Maeztu, que nunca teve outras armas que não fossem as suas ideias? Porque se calam Malraux, Cassou, Huxley, Sinclair Lewis, Thomaz Mann e os seus generosos confrades diante do assassínio de D. Jacinto Benavente, premio Nobel e gloria universal do teatro? (Diário de Notícias, 22 de septiembre de 1936, p. 1).

Ferro mantuvo su convicción en el presunto asesinato de Benavente incluso tras los primeros desmentidos. En una entrevista al periódico Acção no daba crédito a que el dramaturgo siguiera con vida:

Que Jacinto Benavente apareceu entrevistado num jornal depois de nos noticiarem a sua morte? Quem não conhecer a Jacinto Benavente e a sua obra, acredita; os que a conhecem, não. Essa entrevista é apócrifa, não é Jacinto Benavente a falar, a escrever, a discorrer; nada que se pareça como êle (Acção, nº 19, 3 de octubre de 1936, p. 2).

El paroxismo de la manipulación colectiva, desde los primeros meses de contienda, había llegado con el fusilamiento de Federico García Lorca. Los medios del régimen salazarista no negaron, sino que denunciaron el execrablecrimen, imputándolo, eso sí, a los "marxistas de Barcelona", según palabras del propio António Ferro (Diário de Notícias, 22 de septiembre de 1936, p. 1). Se trataba de convertir al irrepetible autor de Romancero gitano en víctima de la barbarie comunista -algo que también se intentó en la propia España sublevada-, al parecer porque "o seu talento era uma afirmação de fascismo", en palabras de quien acabaría siendo jefe de los servicios de información 
del Estado Novo, el periodista Dutra Faria (Acção, no 17, 19 de septiembre de 1936, p. 1). Tal campaña retrasó, sin duda, los ecos del asesinato en los medios de izquierdas, que finalmente acabaron por rescatar para sí la figura del granadino a finales de aquel año (O Diabo, n 131, 27 de diciembre de 1936, p. 8). En cualquier caso, la inclusión de García Lorca durante el verano de 1936 entre las víctimas de la "barbarie comunista" por la prensa salazarista se inscribía en el mensaje tremebundo de una "Espanha vermelha" obsesionada por la destrucción de cualquier vestigio de cultura o inteligencia. El punto álgido de tales tesis llegó con el manifiesto del 10 de octubre gestado desde el SPN de António Ferro y dirigido al Instituto de Cooperación Intelectual de la Sociedad de Naciones que se publicó en numerosos medios portugueses afectos y en algunas cabeceras brasileñas y alemanas. En sus dos primeros párrafos se contiene la imagen arquetípica construida a propósito del bando republicano español en la propaganda salazarista:

Alguns dos mais ilustres escritores, artistas e jornalistas espanhois do nosso tempo, tudo
leva a crêr que se encontram detidos nas prisões de Madrid, de Barcelona, de Valencia ou de
Alicante, pelo crime ou meras suspeitas de não pensar conforme das doutrinas representadas
pelo govêrno que domina algumas regiões de Espanha. Outros foram executados, sem culpa ou
aparencias de julgamento; todos os que sobrevivem e não puderam acolher-se á hospitalidade
de paises estrangeiros ou refugiar-se nas regiões em que o Exército conseguiu impôr uma ordem
civilizada correm o risco de serem julgados por tribunais odiosos, constituidos por individuos
fanatizados pelas mais ásperas paixões políticas e sem cultura para avaliarem o que representa
como atentado ao Espirito a execução de alguns dos maiores valores da Espanha actual.

Tem-se destruido, por obediencia a uma determinação sistemática, metodicamente, diabolicamente executada, o patrimonio artistico da Espanha, cujo valor histórico e humano têm ás vezes aspectos que parecem sobrenaturais. E, nessa obra destruidora, em odio tenacissimo a tudo o que é nobre e superior, seja a pedra redilhada duma catedral ou dum castelo de outrora, a virtude duma mulher ou a grandeza dum heroi, julga ver-se a intenção satanica de destruir tudo, com o objetivo infantil de construir do "nada" as vagas aspirações arquitectadas em momentos de alucinação (Diário da Manhã, 10 de octubre de 1936, pp. 1 y 7).

El manifiesto fue firmado por varios centenares de artistas, escritores e intelectuales del país, entre los que destaca, como ninguna, la rúbrica del padre del simbolismo luso, Eugénio de Castro. Otros firmantes de primer orden fueron los poetas António Correia de Oliveira, Carlos Queiroz, Afonso Lopes Vieira o José Blanc de Portugal, además de los escritores Agostinho de Campos y Teresa Leitão de Barros, el periodista Joaquim Manso, el cineasta António Lopes Ribeiro o el futuro sucesor de Oliveira Salazar en la dirección del Estado Novo, el profesor Marcelo Caetano, entre otros (Pena Rodríguez, 1997: 251-252).

El "genocidio rojo" fue casus belli de la propaganda salazarista durante toda la contienda. En la aclamada conferencia que Wenceslao Fernández Flórez ofreció en la sede del SPN en calidad de "superviviente" de "O Terror Vermelho" el 8 de junio de 1938 en Lisboa, el tema resultó ineludible. La alocución de Fernández Flórez y la presentación de Ferro recordaron la falsa noticia, dos años atrás, sobre la muerte del escritor gallego, lo que traía a colación nuevamente la lista de intelectuales ciertamente asesinados por fuego republicano. Así lo dejaron patente los medios periodísticos del régimen: 


\begin{abstract}
Flores acabou por conseguir da Espanha vermelha, salvar-se, mas não fácilmente, não como quem parte, com a sua bagagem feita, a horas certas. Salvou-se, para bem de nós todos, para nossa alegria, mas como aqueles raros condenados á morte que conseguem libertar-se, quando a noite desce, dum monte de cadáveres que se forma após os fuzilamentos em massa. Conseguiu salvar-se mas deixando nesse monte de cadáveres intelectuais como Ramiro de Maeztu, Manuel Bueno, Salazar Alonso, Muñoz Seca e tantos outros, testemunha implacável, justiceira, salvouse para nos vir contar o que os seus olhos viram, o que a sua alma sofreu! (Diário da Manha, 9 de junio de 1938, p. 4).
\end{abstract}

Debido al éxito del testimonio de este ilustre "superviviente", el Diário de Noticias publicó en las siguientes semanas una serie de quince crónicas escritas por el propio Fernández Flórez sobre las peripecias sufridas para burlar la muerte en el Madrid republicano. Fruto de estas crónicas se editará el libro exento O Terror Vermelho (Lisboa, Emprêsa Nacional de Publicidade, 1938), en cuyo prólogo el autor de Volvoreta denunciaba lo que entendía como la sovietización de España bajo la bandera de la República:

As ideias eram russas, os processos eram russos, russos eram os homens chegados para dirigir até as matanças; russas as armas, russas as conservas que, ao princípio, deram ao povo, russos os nomes que se invocavam, as denominações das brigadas, os originais dos grandes retratos que presidiam aos comícios e às deliberações (p. 12).

Conforme la evolución de la guerra fue decantando el pulso bélico en favor del bando sublevado, se hizo necesaria una mayor institucionalización de las relaciones entre los gobiernos de Lisboa y Burgos, lo que también atañía a sus instituciones culturales. En busca de cierta legitimidad internacional, se aderezó la gran sintonía de ambos gabinetes con el hermanamiento de sus instituciones culturales de mayor prestigio. En este contexto se realizaron diversos viajes y encuentros con estudiantes universitarios en territorio sublevado, así como actos emblemáticos de hermanamiento en foros de relumbrón como la Universidad de Coímbra. La vinculación de esta última con el gobierno del Estado Novo fue estrecha desde un principio. No pocos miembros de los gabinetes de Oliveira Salazar estudiaron o enseñaron en la universidad conimbriguense, empezando por el propio dictador. El régimen salazarista protegió y cultivó tan prestigioso órgano educativo como epicentro mismo del "espíritu científico" que alimentaba teóricamente al Estado Novo, en un ejercicio preciso de lo que Unamuno había denominado como "fascismo de cátedra" (Ahora, 3 de julio de 1935 , p. 5). Entre los muchos actos laudatorios y de regocijo nacional en tan decisivo momento histórico para ambos regímenes, nos interesan sobremanera dos de ellos. El primero se celebró un 11 de mayo de 1938 en la sede de la Academia de España situada en el propio campus de Coímbra. En ella el director de la Facultad de Letras, a la sazón el poeta Eugénio de Castro, recibía un solemne homenaje de sus vecinos españoles. Autoridades culturales del franquismo como el duque de Maura -presidente de la Academia de la Historia-, Lasso de la Vega, el marqués de Villaurrutia o, sobre todos ellos, Eugenio d'Ors, dieron las ínfulas deseables para tan elevado acto. En la célebre Sala dos Capelos la crema de la intelectualidad franquista hizo entrega al padre del simbolismo portugués de la palma honorífica (Diário de Lisboa, 12 de mayo de 1938, p. 5). El autor de Oaristos no dudó en relacionar los honores recibidos como amigo predilecto de España con las circunstancias bélicas del momento: 


\begin{abstract}
A vinda a Coimbra de tão luzida embaizada intelectual, que em qualquer ocasião seria honrosissima para mim, para esta Universidade e para Portugal, mais honrosa se torna ainda pela circunstancia de se realizar no momento em que, ao cabo de dois anos de tremenda carnificina, a Espanha heroica, a Espanha nacionalista vê finalmente aparecer e pairar sôbre o fragor dos ultimos combates, o vulto fulgurante da vitoria, que há-de reintegrá-la na dupla grandeza que lhe compete, pela altiva consciencia do seu passado e pela inabalável fé com que olha para o futuro. A vinda a Coimbra para festejar um simples põeta, constitue uma afirmação de idealismo heroico, pois mostra como os vôos do espirito, mais perto dos astros do que das paixões humanas, passam incólumes sôbre o troar dos canhões e o sibilar das metralhadoras (...) sinceramente me congratulo por ter sido eu o pretexto desta nova afirmação da fraterna amizade dos dois gloriosos povos da peninsula. Agradeço comovidamente todas as demonstrações de estima que acabo de receber e termino, clamando do fundo do coração: Arriba Espanha! Viva Portugal! (Diário da Manhã, 14 de mayo de 1938, p. 8).
\end{abstract}

En cierto sentido celebrado como segundo acto de una misma representación teatral, el 11 de diciembre del mismo año Eugenio d'Ors regresaba a la Sala dos Capelos de la Universidad de Coímbra. En esta ocasión lo hizo como protagonista. Su investidura como doctor honoris causa contó con la presencia de Nicolás Franco y buena parte de su "embajada negra" en Lisboa. Hubo en tal acto gran profusión de uniformes falangistas y de la Mocidade portuguesa y tuvo por colofón la inauguración de una Sala Española en la Facultad de Letras (Diário da Manhã, 12 de diciembre de 1938, p. 1). Con este doble acto, y mediante las figuras emblemáticas de Eugénio de Castro y Eugenio d’Ors, se trasladaba un mensaje claro y preciso, según el cual la más alta cultura -encarnada en estos dos pesos pesados del modernismo ibérico, largamente implicados en los contactos culturales entre ambos países desde principios de sigloestaba del lado de los nuevos regímenes dictatoriales. Se trataba, a la postre, de un calculado proceso de institucionalización cultural común que ayudara a engrasar las complejas relaciones de amistad, necesidad y recelo mutuos entre el Estado Novo y la dictadura franquista, tan puntualmente expresados en el Tratado de Amistad y No Agresión firmado en Lisboa el 17 de marzo de 1939 entre Oliveira Salazar y Nicolás Franco, embajador de un bando ya vencedor de facto en la guerra de España.

\title{
2. POESÍA SALAZARISTA PARA LA “GUERRA DE ESPANHA”
}

Como sucediera con los jóvenes del neorrealismo portugués de izquierdas, una serie de mitos en torno a la "guerra de Espanha" vendrán a configurar todo un ideario moral al servicio de la creación poética -rendida esta, a su vez, a la consigna política-. $\mathrm{Si}$ en los autores que sintonizaron con el bando republicano el asesinato de Federico García Lorca, la figura de Dolores Ibárruri "Pasionaria” o el bombardeo sobre Guernica fueron leitmotiv de numerosos textos en verso y prosa -véase la citada antología de Namorado, sin ir más lejos-, entre los intelectuales del salazarismo encontraremos fuertes resonancias a propósito de la resistencia del Alcázar de Toledo, los voluntarios del nacionalismo portugués conocidos como Os Viriatos, o la figura del propio general Francisco Franco. Al autoproclamado Caudillo dirigirá por valija diplomática sus Poesias dedicadas ao Grande FRANCO Joaquim Monteiro. Bajo tan declarativo título encontramos un previsible ramillete de odas consagradas a cantar las virtudes del "Generalísimo" como líder total de España: 


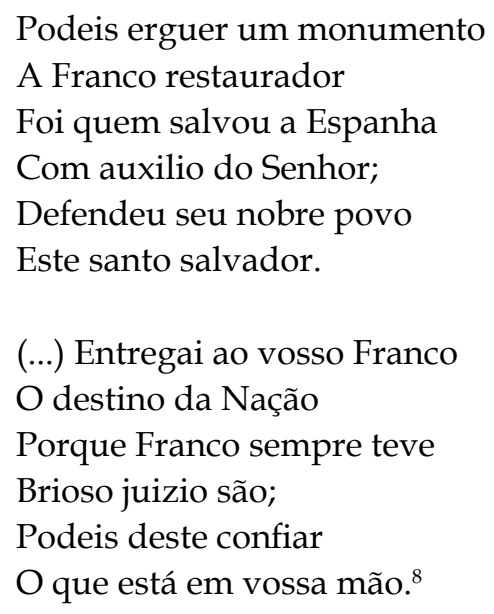

No fueron pocos los poemas de celebración a propósito de las hazañas "nacionales" publicados en la prensa periódica portuguesa, hasta el punto de funcionar como uno de los grandes recursos propagandísticos del momento. Pena Rodríguez señala numerosas colaboraciones firmadas por poetas portugueses en la prensa del salazarismo. Entre dichas firmas encontramos las de Cassilda de Castro, Acácio de Paiva, António Correia de Oliveira, António de Cértima, Felix Correia, Silva Tavares, Sidónio Miguel o Graciette Branco, entre otros (Pena Rodríguez, 1997: 300).

A lo largo de estos convulsos meses -convulsos también en Portugal, aunque fuera en sordina y bajo el vigilante régimen de Oliveira Salazar-, prensa y poesía se pusieron explícitamente al servicio de la guerra propagandística. El ámbito cultural era un terreno especialmente delicado ante sucesos como el clamado asesinato de Federico García Lorca o los devaneos del imprevisible Miguel de Unamuno. Era por ello de especial interés para la maquinaria periodística de los sublevados y sus aliados portugueses -en este ámbito mucho menos disimulados que en lo militardesacreditar y mermar en lo posible el halo "intelectual" con el que otras opiniones públicas como la británica o la norteamericana investían a los republicanos. También era de especial interés arremeter contra sus líderes sociales o sus mandos militares. De esta manera, junto a los poemas de exaltación nacionalista menudearon por Portugal no pocas composiciones de sátira y escarnio contra los principales símbolos del bando leal a la República. Tal fue el caso del general Miaja, quien en un discurso radiofónico se había aventurado a pronosticar una futura "liberación" de Portugal. En respuesta directa, fue dirigido contra él este soneto publicado en el principal periódico del país:

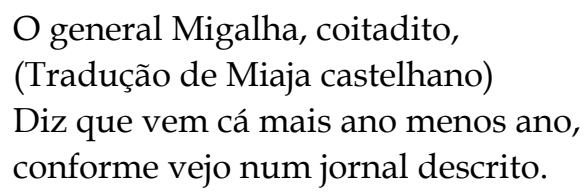

\footnotetext{
${ }^{8}$ Estas Poesias dedicadas ao Grande FRANCO se conservan en el Archivo General de la Administración, Exteriores, caja nº 6641. Tomado de (Pena Rodríguez, 1997: 206).
} 
Em todo caso, venha seu Migalha!

Aceitam de bom grado o desafio

Pelo menos os pombos alfacinhas

Aos quais fazemos festas quando calha

E estão sempre ansiosos no Rossio

Por que a gente lhe deite migalhinhas.

(Diário de Notícias, 14 de abril de 1937, p. 1).

Firmaba tan sintomático soneto Acácio de Paiva ${ }^{9}$, muestra paradigmática de toda esta poesía en cuanto la amenaza de un "contagio" soviético en el propio Portugal si los republicanos vencían era, precisamente, la gran motivación ideológica de los voceros del franquismo al otro lado de la Raya.

Entre el escarnio del enemigo y la exaltación de los nacionalistas españoles, elevados a la categoría de redentores de su patria, pivotará esta poesía salazarista al servicio de los militares sublevados en la "guerra de Espanha". Un abundante y reconocible corpus poético que encontró en toda esta poesía de prensa, pero también en poemarios elaborados y especialmente alumbrados para la "causa" su medio de expresión.

\subsection{Empieza la guerra. El Arriba, Espanha! de Ruy Correia Leite (1936)}

Probablemente uno de los poemarios más representativos de toda esta lírica filofranquista de ocasión sea el Arriba, Espanha! (Lisboa, Sociedad Nacional de Tipografía, 1936) de Ruy Correia Leite ${ }^{10}$. Dedicado “Aos Gloriosos Chefes do Exército Espanhol. A todos Aqueles que oferecem a sua vida pela Espanha e pela Civilização Ocidental", en el poemario de Correia Leite se reúnen diez sonetos consagrados a lugares emblemáticos de la naciente contienda y dedicados a algunos de los principales militares del bando nacionalista ${ }^{11}$. En el primero de ellos el sonetista expone abiertamente el objetivo propagandístico de su poemario:

Não pretende êste livro, a que eu empresto

Tôda a ternura com que foi escrito,

Sêr um livro de versos. É um grito,

Um grito de revolta e de protesto!

\footnotetext{
${ }^{9}$ Acácio de Paiva nació en Leiria un 14 de abril de 1863. Licenciado en farmacología por Oporto, se preció de poeta y traductor literario, colaborando en medios como O Século, Diário de Notícias, Ilustração Portuguesa y O Mensageiro. Falleció en Olival, en Ourém, un noviembre de 1944.

${ }^{10}$ Correia Leite (1908-1973) firmó muy diversos textos dramáticos, versos y canciones, predominantemente de espíritu reaccionario. Entre sus libros destacan Portugal dos pequeninos (Lisboa, Parceria António Maria Pereira, 1932), Raça (Lisboa, Editorial Aviz, 1944) y O auto da mocidade (Lisboa, 1944).

${ }^{11}$ Los sonetos son "Razão" (p. 3); “Espanhóis", dedicado al general Franco (p. 4); “Burgos”, dedicado al general Mola (p. 5); "Sevilha", dedicado al general Queipo de Llano (p. 6); "Badajoz", dedicado al coronel Yagüe (p. 7); “Cierro de los angeles" (p. 8); “Toledo" (p. 9); “Irun” (p. 10); “Saragoza” (p. 11); y

"Arriba, Espanha!", dedicado al general Cabanellas (p. 12).
} 
É atacar vibrante pelo gesto,

Pela palavra, em ânsias de infinito,

Um govêrno satánico e maldito

Que nem govêrno chega a ser, de resto.

É defender o Génio e o Pensamento,

Um altar, uma ideia, um monumento,

A familia, a Verdade, a Tradição!

Tudo o que canta é tudo o que redime;

É atacar a estupidez e o crime!

É defender a Civilição!

(Ruy Correia Leite, Arriba, Espanha!, p. 3).

Bajo esta idea de redención y defensa de la "civilización" -civilización solo posible bajo el estrecho marco nacional y católico propugnado por los regímenes de António de Oliveira Salazar o Francisco Franco- se articula el recorrido sonetístico propuesto por Correia Leite y específicamente expuesto en el soneto "Espanhóis", consagrado a estos y dedicado "Ao General Franco" en persona:

E a onda humana vai, como uma cheia,

Colgando os montes, dominando as aristas,

Nessa avançada audaz que não receia

As sanguinárias hordas comunistas.

São tercios, requetés e falangistas

Que palmo a palmo, aldeia após aldeia,

Em acções de bravura nunca vistas

Na História escrivem mais uma epopeia!

É o glorioso exército que avança!

Não pára, não recua, não se cansa,

porque é composto apenas por heróis!

Sabem bem o que querem, são concretos.

Não podemos chamar-lhes: Insurrectos.

Devemos só chamar-lhes: Espanhóis!

(Ruy Correia Leite, Arriba, Espanha!, p. 4).

Bajo la noción de "reconquista" cristiana, que tan del gusto de ciertos sectores del franquismo sería y que tantas protestas y ampollas levantaría entre los "laínes y ridruejos", cada batalla era pasto para la epopeya y cada victoria una proeza consagrada al altar de la cristiandad y la épica. Y ello aunque fuera a despecho de polémicas como la suscitada en la comunidad internacional -denunciada entre otros por el corresponsal del Diário de Lisboa Mário Neves- tras la cruenta entrada en Badajoz de las tropas sediciosas comandadas por el coronel Yagüe. Dedicado al propio Yagüe, el soneto "Badajoz" erige en "mártir" a la maltrecha ciudad extremeña:

Provincia mártir, o teu nome fica

Para sempre na História desta guerra!

Grito de dôr da ensanguentada terra

Que outrora foi tão fértil e tão rica. 
Exemplo edificante em que se encerra

O mal que a gente estúpida pratica;

Gente que mata e queima e crucifica,

Num clamor a rolar de serra em serra!

Odios acesos, bárbaras vinganças,

A vitimar os velhos e as crianças,

Risos em flôr que um tiro emudeceu!

E eu julgo vêr uns olhos pequeninos, Ingénuos, a fitar os assasinos

E a perguntar-lhes; Mas que mal fiz eu?

(Ruy Correia Leite, Arriba, Espanha!, p. 7).

No obstante, si hubo un episodio y un lugar que se prestó como ninguno a la épica y la propaganda franquistas esa fue la ciudad de Toledo. La resistencia al asedio republicano de las tropas sublevadas en el Alcázar y su posterior "liberación" vino a conformar en el imaginario colectivo del bando vencedor una suerte de símbolo, por metonimia, de todo el país. No en vano, en la poesía portuguesa afecta a los nacionalistas la capital del Tajo castellano fue uno de los temas predilectos. No podía faltar, desde luego, entre los sonetos de Correia Leite.

Vivido dia a dia, há mais dum mês

Que nêsse velho Alcácer se condensa

A mocidade heroica, cuja crença

Há-de salvar a Pátria uma outra vez!

Eu penso e, creio, toda a gente pensa:

O que êles fazem nunca ninguém fez,

Vendo a morte de rostros a seus pés

E ao alto o Céu numa aleluia imensa!

Vós podeis, hordas ávidas de sangue

Vivar à volta!... O Alcácer mesmo exangue,

Sem fôrças, desafia a vossa sanha!

Deus não consente e não consente o medo;

Pois destruir o Alcácer de Toledo

Era matar o coração de Espanha!

(Ruy Correia Leite, Arriba, Espanha!, p. 9).

En ese metro especialmente explotado por las plumas afectas al Alzamiento pensemos en la Corona de Sonetos en honor de José Antonio Primo de Rivera (Barcelona, Jerarquía, 1939), entre otros conjuntos- Ruy Correia Leita nos lega en la concisión de sus diez sonetos reunidos al grito de Arriba, espanha! un ejemplar inconfundible de lo que la poesía nacionalista portuguesa encontró en la contienda del país vecino. 


\subsection{Algo más que la Epopeia de Toledo de Freitas Soares (1936)}

La resistencia nacionalista al asedio republicano sobre el alcázar toledano inspirará desde su mismo desenlace numerosos versos de adhesión en Portugal, como los publicados por el propio Ruy Correia Leite, "Toledo", ya en el Diário da Manhã (29 de septiembre de 1936, p. 8); por Ricardo Cruz, "Cadetes de Toledo", en A Voz (11 de octubre de 1936, p. 1); o Branca de Gonta Colaço, "O Alcázar”, en el Diário de Lisboa (16 de noviembre de 1936, p. 10). No en vano, tal suceso dará título al poemario más completo y arquetípico de toda esta lírica de exaltación filofascista. Nos referimos a la Epopeia de Toledo, alumbrada en su primera edición (Oporto, Tip. Gonçalves \& Nogueira, 1936) con nueve poemas firmados por un casi desconocido António de Freitas Soares ${ }^{12}$ y presentada como "Homenagem dum português ao maior dos portugueses ilustre Presidente do Conselho Exmo. Senhor Doutor Oliveira Salazar".

El libro de Freitas Soares tuvo un éxito considerable, a juzgar por la salida a finales de ese mismo año de su segunda edición (Oporto, Tip. Domingo de Oliveira, 1936). En ella se recogen ya un total de diecinueve composiciones poéticas además de diversas láminas con cartelería salazarista o los retratos de Francisco Franco y de Oliveira Salazaris. De la acogida de sus versos da cuenta la segunda edición de Epopeia de Toledo, terminada de imprimir según su colofón el 14 de diciembre de 1936 y precedida por una serie de recortes de prensa con elogiosas "Referências da Critica" (pp. 9-24) ${ }^{14}$ y “Cartas" de felicitación (pp. 25-40) entre las que se cuenta una dirigida por el propio general Mola ${ }^{15}$. Es la Epopeia de Toledo de Freitas Soares en su edición definitiva, "ampliada com os principais episódios espano-luso-soviéticos desde Toledo a Madrid", un artefacto paradigmático de la propaganda literaria en favor de

\footnotetext{
${ }^{12}$ Nacido en la freguesía de Creixomil, Guimarães, el año de 1891, publicó diversos poemarios de irregular valía y tono siempre patriotero. Trabajó como agente comercial y publicó la mayor parte de su obra en la ciudad de Oporto. Entre sus libros encontramos A Gago Coutinho (1931), Templo da Pátria (1938), Luar da minha Pátria (1941), Exaltação Lusíada (1947) y Poemas (1952).

${ }^{13}$ En la primera edición aparecieron los poemas "A Roda desta Vida" (pp. 7-10), "Garras Dantescas" (pp. 11-12), "Defendendo a Pátria" (pp. 13-14), "Voz da Chamada" (pp. 15-16), "Hospitalidade Portuguesa" (pp. 17-20), "A Tormenta Espanhola" (pp. 21-22), "A Tomada de Toledo" (pp. 23-24), "Féras Paixões" (pp. 25-26) y "Fé e Patriotismo" (pp. 27-28). En la segunda edición se añadieron diez poemas y se reestructuraron en tres secciones -"Preâmbulo" (pp. 43-67), "A Tomada de Toledo" (pp. 71-73) y "Fé e Patriotismo" (pp. 79-91)-, siendo los diecinueve poemas los siguientes: "A Roda desta vida" (pp. 43-44), “O Meu Exlibris" (pp. 45-46), “Portugal Maior" (pp. 49-53), “Garras dantescas" (pp. 57-59), "Defendendo a Pátria" (pp. 60-61), "Voz da Chamada" (p. 62), "Hospitalidade Portuguesa" (pp. 6364), "A Tormenta espanhola" (pp. 65-67), "General Moscardó e os seus Cadetes" (p. 71), "Violação da Fronteira" (p. 72), “Devolução dos Bolchevistas" (p. 73), "Fé e Patriotismo" (pp. 79-80), "Féras Paixões" (pp. 81-82), "O Lar Cristão" dedicado "As mãis portuguesas" (pp. 83-84), “A Passionária" (pp. 85-86), "A Neutralidade" dedicado "A todos os bons portugueses" (p. 87), "Corte de Relações com Madrid" (p. 88), "Cristo nas Escolas" (p. 89) y "Pátria de Camões" (pp. 90-91).

${ }^{14}$ Se compilan reseñas de diversos medios de la prensa salazarista como Jornal de Notícias, O Primeiro de Janeiro, A Voz, Diário da Manhã, O Comêrcio do Porto, Jornal de Louzada, Notícias de Guimarãis y O Comércio de Guimarãis, entre otros.

${ }^{15}$ Entre los emisarios de aquellas cartas de felicitación encontramos entre otros al capitán Manuel José de Silva, el pintor Abel Cardoso, el comandante militar de Vigo o el mencionado general Emilio Mola, con una carta fechada el 3 de noviembre de 1936.
} 
los sublevados en el Portugal salazarista de aquel tiempo. En sus páginas encontramos desde los consabidos poemas de glorificación al "Caudillo":

Quando um bom comandante como Franco

Como êsse heroi general,

Chefe do Estado español

-Admirado em Portugal-

Que os nacionalistas num arranco,

Guiados por doirado sol,

Proclamaram com fé e patriotismo,

Toma o supremo comando

É mais que certo que o brutal abismo

Por onde a Espanha ia resbalando

Há-de ser bem entulhado

(Freita Soares, Epopeia de Toledo, 2a ed., p. 79),

a asuntos tan escasamente poéticos como las "devoluciones" de los exiliados republicanos en las fronteras portuguesas -como le sucederá tres años más tarde a Miguel Hernández- en "Violação da Fronteira" y “Devolução dos Bolchevistas" (2o ed., pp. 72-73).

La preocupación por la amenaza soviética -nexo de unión fundamental entre el salazarismo y la causa de los militares españoles rebeldes- conforma el espíritu de todo el libro en una visión antagónica y maniquea entre el bien, representado por el cristianismo ibérico, y el mal, encarnado en las "Garras Dantescas" del comunismo:

Cándida e estranha pomba moscovita,

Símbolo da igualdade fraternal,

E como é belo o teu lindo pombal!...

Se a fogueira arde, alastra e crepita;

fôgo que ameaça a Paz de Portugal!

O lôbo despe a pele de cordeiro,

Os seus instintos correm pelo mundo

A transformar a Terra num braseiro

E os bons cristiãos sofrendo amor profundo!...

-Sem lei, e as leis de Deus a profanar,

'Stende as garras a fera de Moscovo

E o espectro de Lenine a gargalhar,

Rege a dança macabra do seu povo,

Prometendo um mundo novo!!... (...)

(Freitas Soares, Epopeia de Toledo, 2a ed., p. 57).

Como pavoroso fantasma y abominable bestia, el comunismo soviético es presentado por los versos de Freitas Soares en directa acechanza sobre la Península:

(...) Linda e nobre Peninsula Iberica

Onde a barbarie quer sentar arraiais!...

E na verdade a audacia é grande e bélica

Em cortejo infernal de canibais!!... 
-A cólera rompeu os diques da orden

E correndo em tropel devastador

Só deixa escombros -põe tudo em desorden-

Torrentes de ódio avassalando o Amor!...

Bruta guerra civil que enluta a Espanha

E cobre de vergonha a espécie humana!...

Glória satánica do heroi Patranha

Que fomentou a guerra mais tirana!!...

(Freitas Soares, Epopeia de Toledo, 2a ed., p. 59).

En perfecto diálogo, en este contraste absoluto, se presentan los poemas "O Lar Cristão", dedicado a las piadosas madres portuguesas, y "A Passionária", encendida invectiva contra la diabólica dirigente comunista española que en los versos de Freitas Soares se ve rodeada y vencida por las tropas nacionalistas. Es por el contrario la mujer portuguesa en el soneto "O Lar Cristão" remanso de paz y abnegación femenina:

Benditas as mulheres, que vivem para o lar,

Na sagrada missão de Esposas e de Mãis!...

Que fazem do seu peito um adornado altar

E onde a chama do amor arde em mil espirais.

São trancos desta vida, árvores a verdejar,

Do seu ventre brotando esperanças virginais,

Regaço carinhoso, o mundo a harmonizar,

Edificando um Templo em bases imortais!...

Ditosos corações de abnegadas mulheres

Que nos iluminais á luz da Cristiandade,

Erguidos para Deus, formando dignos seres.

A onde não há lar, reina a obscuridade

-Mãi do egoísmo feroz e dos falsos prazeres;

É um mundo a gemer triste e fría orfandade!...

(Freitas Soares, Epopeia de Toledo, $2^{\mathrm{a}}$ ed., pp. 83-84).

En maniqueo contraste, la larga tirada contra "Pasionaria" rezuma espanto y reproche contra aquella supuesta abominación de todas las virtudes que como buenas madres y esposas habían encarnado las mujeres portuguesas en el anterior poema:

Vergonha das mulheres toleradas,

Nesta vida jamais os olhos meus

Vissem as tuas formas disformadas,

Nunca se abrissem êsses labios teus!...

Se do mundo és a grande sedutora,

Infernal "Passionária" de "os sem Deus"

Que deste à luz a obra Malfeitora

Não brilhem mais as estrêlas lá dos céus.

-Avança, retumbante, e, vais sem treguas

A heroica legião conquistadora!...

Prosegue, conquistando agrestes léguas,

Esmagando a serpente destruídora!... 
E dia a dia fulgem vanas 'strêlas

Que hão-de alunmiar numa nova era! (...)

(Freita Soares, Epopeia de Toledo, $2^{\mathrm{a}}$ ed., p.85).

El poeta de Guimarães ofrece, desde luego, una visión antagónica a la adoptada en esas mismas fechas por Miguel Torga o Mário Dionísio ante la heroína comunista. Bajo la inspiración del célebre grito de "Pasionaria”, Miguel Torga escribía por aquellos mismos días su poema "Não passarão", de cariz sombrío y pesimista en abierto constante con el vitalismo de la mujer nueva de Dionísio ${ }^{16}$. Despunta en esta pieza, desde luego, el desencanto por la derrota inminente, solo dignificada por la altura moral de sus cercados héroes:

Não desesperes, Mãe!

O último triunfo é interdito

Aos heróis que o não são.

Lembra-te do teu grito:

Não passarão!

Não passarão!

Só mesmo se parasse o coração

Que te bate no peito.

Só mesmo se pudesse haver sentido

Entre o sangue vertido

E o sonho desfeito.

Só mesmo se a raiz bebesse em lodo

De traição e de crime.

Só mesmo se não fosse o mundo todo

Que na tua tragédia se redime.

Não passarão!

Arde a seara, mas dum simples grão

Nasce o trigal de novo.

Morrem filhos e filhas da nação,

Não morre um povo!

Não passarão!

Seja qual for a fúria da agressão,

As forças que te querem jugular

Não poderão passar

Sobre a dor infinita desse não

Que a terra inteira ouviu

E repetiu:

Não passarão!

(Miguel Torga, Poemas ibéricos, 1965, pp. 74-75).

\footnotetext{
${ }^{16}$ Teresa Araújo analiza el tratamiento de la figura de Dolores Ibárruri en los poemas "Poema da Mulher Nova" de Dionisio y "Não passarão" de Torga en su artículo "Evocações de Passionária. 'Poema da Mulher Nova' e 'Não passarão'", en Revista Faces de Eva. Estudos sobre a Mulher, n 16, 2006, Lisboa, Universidade Nova de Lisboa.
} 
La "Pasionaria” de Torga, que no vería la luz hasta 1952, año de edición de Alguns poemas ibéricos, ofrece la réplica moral a la satánica Dolores Ibárruri de Freitas Soares. Un pulso poético que fue en ocasiones tan encarnizado como los propios combates y en el que los poetas del salazarismo no escatimaron ni versos ni ataques. La disputa por los símbolos en la propaganda no desmereció, en este sentido figurado al menos, de los combates cuerpo a cuerpo por las ciudades españolas entre ambos bandos.

\subsection{Termina la guerra. La Vitória de Espanha de Vieira da Cruz (1939)}

En la misma senda, consumada ya la guerra, se encaminará el poemario de Tomaz Vieira da Cruz bajo el elocuente título de Vitória de Espanha (Luanda, Imprensa Nacional, 1939), dedicado "Aos mortos que reconquistaram a Pátria" (p. 7). El autor de este peculiar libro, destinado en Angola desde 1924 y director del periódico literario Mocidade, había participado en la "Guerra de Espanha" junto al bando nacionalista, vinculado a las filas de "Os Viriatos" y a la Legión española ${ }^{17}$. Así lo afirma el propio autor en las páginas de Vitória de Espanha:
A minha missão lusíada, em África,
foi alterada por um motivo imprevisto.
Ausentei-me durante algum tempo, mas
regresei mais forte, em mais português.
Combai por minha dama, cantando...
(...)
Da minha espátula de boticário fiz alfanje
e também andei na quema. O meu espírito
colonial desembarcou em Algeciras; e o
meu espírito já regressou, condecorado
com muitas penas. Escrevi com elas um
pouco de poesia que aí fica, em louvor
dos mártires e dos héroes.

(Tomaz Vieira da Cruz, Vitória de Espanha, pp. 25-27).

El libro de Vieira da Cruz se compone de dos partes, siendo la primera un conjunto de breves notas en versículos con nociones "explicativas" para el no iniciado en torno a la guerra civil española y el contenido de sus poemas, siempre desde la óptica del bando nacionalista y en provecho de la dialéctica salazarista ${ }^{18}$. A estos versículos introductorios le siguen siete poemas en los que se vuelve a evocar lugares míticos de la contienda española ${ }^{19}$. El metro escogido es el mismo que eligiera Correia

\footnotetext{
${ }^{17}$ Vieira da Cruz habría nacido en la localidad portuguesa de Constância, situada en Ribatejo, en 1900, y fallecido en Lisboa en 1960. La mayor parte de su vida transcurrió, sin embargo, en Angola. Además de Vitória de Espanha publicó varios libros de temática africana como Quissange. Saudade Negra (Lisboa, Bertrand, 1932), Tatuagem. Poesia de África (Lisboa, Bertrand, 1941), Cinco Poesias da África (Lisboa, Bertrand, 1950) o Cazumbi. Poesia de Angola (Lisboa, Bertrand, 1951).

${ }^{18}$ Así en afirmaciones como que "Espanha e Portugal são dois velhos namorados" (p. 25) o que "a verdadeira liberdade é a liberdade da história, dentro da tradição espiritual dos povos que não perderam a sua alma" (p. 23), por citar dos ejemplos.

${ }^{19}$ Los sonetos en cuestión se titulan “Madrid na Paz" (p. 29), "Madrid na Guerra" (p. 33), "Ascensão" (p. 37), "Toledo" (p. 41) “Alcazar" (p. 45), "Tércio Marroquino" (p. 49) y “Espanha” (p. 53).
} 
Leite para su Arriba, Espanha!, el soneto. Al mismo tiempo, no podía faltar, como en el caso de los anteriores poemarios analizados, al menos un par de sonetos dedicados a la resistencia y conquista de Toledo. En el titulado sencillamente “Toledo" encontramos toda la retórica habitual para tan cantado episodio:

Toledo glorioso, em meu cantar eu te saúdo, imortal Toledo! Soube de ti, ouvindo a voz do mar que era tão triste que metia mêdo.

Quasi não quís ouvir o seu falar, falar de pronto, muito em segredo; mas foi o Tejo que lhe foi cantar, e então ouvi o mar, nêste degrêdo!

Tenho sangue de heróeis em minhas águas e lágrimas de santos que são máguas das maiores que no mundo tenho visto...

Mas eis que sinto um outro sonho exangue; nas minhas ondas, de Toledo, o sangue, flutua e brilha em nova cruz de Cristo.

(Tomaz Vieira da Cruz, Vitória de Espanha, p. 43).

Toledo era, en suma, símbolo de la España "victoriosa", igual que esta, y la Península toda, eran reducto y baluarte de la cristiandad. Una lucha con ínfulas no solo de "reconquista" contra el infiel -trasmutado este en rojo en vez de moro-, sino de auténtico sacrificio solo equiparable al padecido por el propio Cristo en su cruz. Así se nos presenta la "Espanha" de Vieira da Cruz en el soneto homónimo:

Do calvário da raça da vitória tal-qual o sol rasgando a tempestade, um grito se levanta, em plena glória, cheio de luz, de sonho e de verdade!

Vai a passar, cantando, a mocidade, Requetés, Viriatos... E a história novas iluminarias de saudade aceita em suas páginas de glória.

Vão a passar os mortos desmentidos, e ninguem acredita que os vencidos fôssem capazes duma acção tamanha!

Silêncio... Agora e sempre, ajoelhai!

Mártir e santa, lá vai Ela, vai, vai a passar a gloriosa Espanha!

(Tomaz Vieira da Cruz, Vitória de Espanha, p. 55).

En este poema de Vieira da Cruz hallamos pues una mezcla de crucifijos y fusiles, de sotanas y uniformes militares, sintomática de la sociedad en la que y para 
la que fueron escritos los versos estudiados en el presente trabajo. Tal es el aliento de estos tres libros. Un espacio para la épica más grandilocuente del nacionalcatolicismo en un tiempo en el que el genocidio al que ambos bandos se entregaron abocaba a tan elevados versos al corto vuelo de la mera propaganda de guerra.

\section{EPÍLOGO. CAMÕES EN CEUTA Y EL CID EN COÍMBRA}

Confusión de héroes legendarios y mandos militares abigarran este particular corpus poético. Acudíamos en nuestra introducción a la imagen de un Camões en Ceuta compadreando con Cervantes, transmutados insospechadamente en un mefistofélico Millán Astray. Cerraremos estas líneas con otra imagen no menos peregrina. Cual perfecto epílogo tardío de aquellos juegos florales al estilo del siglo XIV celebrados en Lisboa, como inconfundible broche de aquellos sonetos de glorificación nacionalista y escarnio republicano firmados por los Vieira da Cruz, Freitas Soares y Correia Leite, en 1949 el propio Francisco Franco era nombrado doctor honoris causa por la Universidad de Coímbra. Le acompañaba en el viaje el otrora director de La gaceta literaria que allá por los años veinte tendiera puentes entre las vanguardias ibéricas, Ernesto Giménez Caballero. Nos brinda a la vuelta Gecé, en su Amor a Portugal, la imagen de un nuevo Cid, nombrado nuevamente en la ciudad del Mondego. Tal "Cid de la Razón" no era otro que "su Caudillo":

Cuando se me dijo que el Caudillo español Franco -como en otros tiempos el Cid-iba a ser nombrado Caballero de la Razón -de Justicia y de Derecho- en la terrible Universidad del "Distingo" y del esotérico rito pombaliano, confieso que me estremecí. Y, sin embargo, Franco fué armado Doctor en Coimbra el 25 de octubre de 1949, a media tarde. Investido de toga y muceta partió de la áurea Biblioteca, en académico cortejo por todo el patio, hasta la Sala de los Capelos: la Sala de la Razón.

(...)¿Qué había sucedido en Coimbra para que la Sinrazón de siglos pasados desapareciera como por milagro de amor ante Franco, volviéndose a los tiempo de Suárez, de Molina, de Granada, del Brocense, de la Reina Isabel, de Doña Mencía, de Doña Inés, del Cid y de Alfonso I el Leonés? ¿Qué había sucedido para poder todos recobrar la Razón perdida?

Pues había sucedido que, hacía veinticinco años, cerca de Coimbra, en la Quinta do Bispo, de Elvas, la Razón -de amor, de poesía, de Alianza-, descendiera como paloma nunciativa sobre el alma de un poeta: Sardinha (¡En el Principio de toda Revolución fué el Verbo!) Y llevada por ese alma genial, tal Razón verdadera comenzó a insinuarse sobre otras almas predestinadas en la doctoral Coimbra: las que formarían la llamada Escuela integralista: la Escuela de la Peninsular Alianza. Soñadores que encontraron, al fin, un realizador de ese sueño: otro profesor de Coimbra llamado Dr. Antonio de Oliveira Salazar.

Ahora, 1949, aquel augurio lejano del poeta se había, decisivamente, convertido en realidad. Haciendo posible que un nuevo Caudillo español fuese aclamado por Juventudes universitarias, por profesores, por todo el pueblo portugués (Giménez Caballero, 1949: 39-40).

De alianzas y poetas, cantores de las ínfulas legendarias que dos regímenes dictatoriales quisieron otorgarse, trataron estas líneas. Un universo propagandístico y literario que circuló sancionado por los estados de Oliveira Salazar y el general Franco por varias décadas y que tuvo en los años de la guerra civil española su particular espacio para el mito y la leyenda, para la más peregrina y sintomática propaganda poética de nuestro pasado siglo XX. 


\section{BIBLIOGRAFÍA}

Ary dos Santos, A. (1936): D. Quixote bolchevick, Lisboa, Livraria Classica Editora.

Becerra Bolaños, A. (1997): "La Guerra Civil de España en la poesía portuguesa", en Actas del V Encuentro de Jóvenes Hispanistas: Las Palmas de Gran Canaria, 25, 26 y 27 de octubre de 1995, Las Palmas de Gran Canaria, Universidad de Las Palmas, 119-126.

Chica Blas, Á. (2012): Cien documentos de archivo. Instituto Español 'Giner de los Ríos' de Lisboa, Madrid, Ministerio de Educación, Cultura y Deporte.

Correia Leite, R. (1936): Arriba, Espanha!, Lisboa, Sociedad Nacional de Tipografía.

Couto Viana, A. M. (1997): Por outras palavras, Lisboa, Vega.

Delgado, I. (1980): Portugal e a Guerra Civil de Espanha, Lisboa, Publicações EuropaAmérica.

De Lorenzo, P. (1973): Y al oeste Portugal, Madrid, Ediciones Cultura Hispánica.

Freitas Soares, A. (1936), Epopeia de Todelo, (1 ${ }^{\mathrm{a}}$ ed.) Oporto, Tip. Gonçalves \& Nogueira. Freitas Soares, A. (1936), Epopeia de Todelo, (2 ${ }^{\mathrm{a}} \mathrm{ed}$.) Oporto, Tip. Domingo de Oliveira.

Giménez Caballero, E. (1949): Amor a Portugal, Madrid, Ediciones Cultura Hispánica. JiménezRedondo,J.C. (1992):Pervivenciay superación del Iberismo:losnuevos condicionantes de la política peninsular (1939-55), Madrid, Universidad Complutense. Tesis doctoral.

Magalhães, J. M. (1999): “Duas trocas com poetas: Portugal e Espanha”, en Rima Pobre, Lisboa, Presença, 279-324.

Namorado, J. (1987): A guerra civil de Espanha na poesia portuguesa, Coímbra, Centelha.

Pena Rodríguez, A. (1997): El Estado Novo de Oliveira Salazar y la Guerra Civil española: información, prensa y propaganda (1936-1939). Tesis doctoral, Madrid, Universidad Complutense.

Pena Rodríguez, A. (2012): “Periodismo, guerra y propaganda: la censura de prensa en Portugal durante la Guerra Civil española", Estudios sobre el Mensaje Periodístico, 18-2, 563-576.

Torga, M. (1965): Poemas ibéricos, Coímbra, Edición del autor.

Vieira da Cruz, T. (1939): Vitória de Espanha, Luanda, Imprensa Nacional. 